\title{
Matemática e arquitetura: uso de fractais em mobiliário urbano
}

\author{
Mathematics and architecture: use of fractions in urban furniture \\ R. S. dos Santos ${ }^{1}$; M. Carasek ${ }^{2}$; R. M. L. Kripka ${ }^{1 *}$; R. A. Lahm ${ }^{3}$ \\ ${ }^{1}$ Instituto de Ciências Exatas e Geociências/ Área de Matemática/ Universidade de Passo Fundo, CEP 99001-970, \\ Passo Fundo, RS, Brasil \\ ${ }_{2}^{2}$ Faculdade de Engenharia e Arquitetura /Área de Arquitetura e Urbanismo/ Universidade de Passo Fundo, CEP \\ 99001-970, Passo Fundo, RS, Brasil \\ ${ }^{3}$ Programa de Pós-Graduação em Educação em Ciências e Matemática (PPGEDUCEM)/ Faculdade de Físical \\ Pontifícia Universidade Católica do Rio Grande do Sul (PUCRS)/, CEP 90619-900, Porto Alegre, RS, Brasil
}

*rkripka@upf.br

(Recebido em 04 de junho de 2018; aceito em 18 de setembro de 2018)

\begin{abstract}
Com objetivo de potencializar o uso de conhecimentos matemáticos em construções arquitetônicas, essa pesquisa foi desenvolvida por professores e estudantes das áreas de Matemática e Arquitetura, onde se discutiu de que modo diferentes padrões fractais poderiam ser aplicáveis à projetos arquitetônicos para gerar mobiliários urbanos inovadores, bonitos, seguros e práticos. O processo metodológico envolveu pesquisa teórica sobre padrões fractais e de estruturas arquitetônicas e também a exploração analítica e propositiva voltada à realização de projetos arquitetônicos, envolvendo mobiliários urbanos que utilizassem na sua concepção a lógica fractal. Como resultado, se obteve uma proposta de projeto de ponto de ônibus, elaborado a partir de dois padrões fractais específicos, escolhidos dentre diversos pesquisados. Conclui-se que a pesquisa realizada contribuiu significativamente com a construção de conhecimentos interdisciplinares, onde o uso dos padrões fractais possibilitou perceber uma aplicação prática dessa teoria matemática, em projetos de Arquitetura e Urbanismo, bem como favoreceu perceber uma proposição visual inovadora para o projeto de mobiliário urbano proposto.

Palavras-chave: Mobiliário urbano. Geometria fractal. Arquitetura e Urbanismo.
\end{abstract}

Aiming to potentialize the use of mathematical knowledge in architectural constructions, this research was developed by professors and students of Mathematics and Architecture, where it was discussed in which way different fractal patterns could be applied to architectural designs, in order to generate innovative, beautiful, safe and practical urban furniture. The methodological process has involved theoretical research on fractal patterns and architectural structures, as well as the analytical and propositive exploration focused on the realization of architectural designs, involving urban furniture, that used in its design, the fractal logic. As result, a proposal for a bus stop design was obtained, which was elaborated from two specific fractal patterns, chosed among several researched ones. It is concluded that the research contributed significantly to the construction of interdisciplinary knowledge, in which the usage of the fractal patterns allowed to perceive a practical application of this mathematical theory in designs of Architecture and Urbanism, as well as favored to perceive an innovative visual proposition for the project of proposed urban furniture.

Keywords: Urban furniture. Fractal geometry. Architecture and Urbanism.

\section{INTRODUÇÃO}

A forma arquitetônica é interdependente das formas geométricas. Sua presença é notada tanto em um simples edifício prismático comum em todas cidades, resultado de estudos da geometria convencional, quanto em qualquer outra edificação com formas mais complexas, que são traçadas a partir de novos conceitos geométricos, com o auxílio de novas ferramentas de computação.

Souza (2008) [1] destaca que existe uma relação importante entre formas arquitetônicas e formas geométricas. Esse autor afirma que se verifica a presença da geometria euclidiana na formulação e na definição de atuais formas arquitetônicas, bem como os conceitos da geometria não euclidiana, tais como os dos fractais, da biônica ou da topologia, que tem contribuído com a transformação das formas arquitetônicas. Além disso, o autor destaca que os recursos 
tecnológicos computacionais têm facilitado a experimentação de novas formas arquitetônicas e suas realizações.

Compreende-se arquitetura como obra construída e sabe-se, por meio da história da evolução humana, que ela existe desde que o homem sentiu a necessidade de ter um teto para se abrigar e se proteger [1,2]. Destaca-se que a matemática, conforme Forbes e Dijksterhuis (1963) [3], tem suas origens relacionadas ao desenvolvimento da ciência, se constituindo num instrumento fundamental em sua evolução. Os autores também salientam que os avanços da matemática e das ciências sempre estiveram relacionados aos avanços sociais e intelectuais das sociedades.

Desse modo, considerando-se que o conhecimento matemático está presente em diversas áreas do conhecimento e tem possibilitado avanços inegáveis para o desenvolvimento das ciências e de toda a humanidade, verificou-se a necessidade de se buscar uma aproximação entre as áreas da Matemática e da Arquitetura visando perceber novas perspectivas na elaboração do espaço projetado e construído.

Inicialmente, Waihrich et al. (2010) [4], com objetivo de aproximar as áreas de Arquitetura e Urbanismo e Matemática, propuseram um projeto de pesquisa interdisciplinar visando identificar padrões da geometria fractal e suas aplicações em arquitetura e urbanismo na busca por novas propostas arquitetônicas que fossem inovadoras, bonitas, seguras e práticas.

Posteriormente, com o intuito de potencializar o uso de conhecimentos matemáticos em construções arquitetônicas, desenvolveu-se a presente pesquisa envolvendo professores e estudantes das áreas de Matemática e Arquitetura, na qual se discutiu de que modo diferentes padrões fractais poderiam ser aplicáveis a projetos arquitetônicos na intenção de gerar mobiliários urbanos inovadores, bonitos, seguros e práticos.

Apresenta-se, em seguida, a fundamentação teórica considerada e o procedimento metodológico desenvolvido, os quais possibilitaram identificar de que modo poderia ser realizada a aplicação de padrões fractais na proposição de um ponto de ônibus; de modo a obter uma proposição visual inovadora para o projeto de mobiliário urbano proposto.

\section{FUNDAMENTAÇÃO TEÓRICA}

Le Corbusier (2014, p.5) [5] declara que "[...] arquitetura deve ser entendida como uma das mais urgentes necessidades do homem. [...].”. Também afirma que como:

[...] coisa de emoção plástica, deve, no seu domínio, começar pelo começo também e empregar os elementos suscetíveis de atingir nossos sentidos, de satisfazer nossos desejos visuais, e dispô-los de tal maneira que sua visão nos afete claramente pela delicadeza ou pela brutalidade, pelo tumulto ou pela serenidade, pela indiferença ou pelo interesse; esses são elementos plásticos, formas que os nossos olhos veem claramente, que nosso espirito mede ([5], p.7).

Na Arquitetura, Ching (2012) [6] define "forma" como um termo abrangente, com vários significados, que inclui um sentido de massa ou volume tridimensional. Ao assumir formato com tamanho, cor, textura, orientação e posição definidos, a composição da forma deverá compor unidade com o espaço - unidade de opostos.

Desse modo, tendo em vista a definição de forma idealizada, o processo de produção de uma obra construída deve passar, obrigatoriamente, pela elaboração e pelo desenvolvimento de um projeto arquitetônico que pode ser descrito por Silva (1991, p.39) [7] como "[...] proposta de solução para um específico problema de organização do entorno humano".

Destaca-se que, no final de década de 1970, surgiu a geometria fractal com os estudos do matemático Mandelbrot $(1983,1998)$ [8, 9], a qual também foi usada como uma alterativa aos métodos convencionais de representação em Arquitetura. Nessa época, o paradigma na Arquitetura é o movimento chamado de pós-modernismo.

Segundo Sedrez e Pereira (2012) [10], Peter Eisenman desenvolveu, em 1985, o projeto "Moving Arrows, Eros and other Errors", no qual já usava geometria fractal como um instrumento de design de forma. Desde então, percebeu-se que, no projeto arquitetônico, 
poderiam ser utilizados os princípios dos padrões fractais de modo a reproduzir a otimização de recursos e a beleza da simetria observadas em elementos da natureza. Barthel (1985, p. 88) [11] indica que esse tipo de projeto "[...] faz parte de uma série de outros que se fundamentam na observação e interpretação dos elementos da natureza para a definição das formas arquitetônicas".

Destaca-se que, apesar de ainda não existir uma caracterização única do conjunto fractal, a ideia intuitiva desse conceito refere-se a um conjunto no qual está inserida uma cópia reduzida de si mesmo, podendo ou não ser acompanhado de deformações. Alguns desses conjuntos podem ser construídos para servir de exemplos de um problema matemático enquanto que outros aparecem naturalmente no estudo de alguns problemas reais $[8,9,12]$.

Assim, os padrões fractais são desenvolvidos de modo a possibilitar a criação de formas e volumes semelhantes aos diversos padrões encontrados na natureza por meio de diferentes estratégias matemáticas. Geralmente, relacionam-se a animais ou plantas revelando soluções ou habilidades desenvolvidas durante a evolução das espécies para superar as dificuldades impostas pela natureza, que podem ser associadas à ideia de soluções estruturais, tais como camuflagem para proteção ou de adaptação hidrodinâmica [13]. Atualmente, os fractais têm auxiliado no desenvolvimento de várias áreas do conhecimento como a engenharia, as comunicações telefônicas, a química e as artes, entre outras.

Segundo Barbosa (2002) [13], aproximadamente na década de 1950, Mandelbrot, trabalhando nos Estados Unidos na International Business Machines (IBM), deparou-se com o problema de ruídos eletrônicos existentes em linhas telefônicas usadas em rede entre computadores. $\mathrm{O}$ autor afirma que os engenheiros da época, devido à irregularidade e à aleatoriedade dos sinais, não estavam conseguindo eliminar a interferência de tais ruídos nos sinais e, para resolver o problema, Mandelbrot utilizou um trabalho antigo de George Cantor, chamado Poeira de Cantor, entendendo os erros de transmissão como um desses conjuntos.

Como exemplos de pesquisas mais recentes podem ser citadas as investigações de Baptista (2013) [14] que elaborou uma dissertação sobre aplicações de fractais na engenharia, ou ainda, a tese de Bernardes (2014) [15], na área da Química, na qual o pesquisador constatou que a reação química da atividade catalítica apresentou uma relação direta com padrões fractais.

Outro exemplo seria a investigação realizada por Cruz et al. (2008) [16] sobre "Codificação fractal de imagens" na qual indica que as técnicas fractais, quando combinadas com outras técnicas para codificação e transmissão de imagens, possibilitam um salto de desempenho percebido tanto em termos de qualidade visual quanto em termos de tempos de processamento das imagens. Outro exemplo interessante refere-se ao uso de padrões fractais na área da medicina, os quais têm sido utilizados em novas descobertas e avanços significativos, em particular no tratamento de doenças crônicas, estudo da arritmia cardíaca e diagnóstico do câncer [17, 18].

Os padrões fractais, pelas possibilidades que oferecem como elementos estéticos, podem ser utilizados em estruturas otimizadas que visem ao uso racional de recursos, tanto como um elemento da própria estrutura quanto como elementos de iluminação ou ventilação e, desse modo, têm despertado o interesse de muitos engenheiros e arquitetos [4]

Salingaros (2004) [19] afirma que todos os organismos biológicos se organizam conforme leis básicas e comuns e essas leis obedecem a padrões fractais que são naturais e intrínsecos ao ser humano. Assim, sugere que as leis básicas de arquitetura e urbanismo mostram que tanto um edifício quanto uma cidade estão sujeitos às mesmas leis organizacionais de um organismo biológico e um programa computacional complexo. Também defende que a nova arquitetura depende de regras científicas em vez de preceitos estilísticos e que, usando essas regras, podem ser criados edifícios que aumentam os sentimentos intensamente positivos, tais como os gerados pelos maiores edifícios históricos sem copiar nem sua forma, nem seu estilo.

Salingaros (2004) [19] indica que tipologias urbanas usadas até o século XX conduzem à ideia de uma estrutura fractal, destacando que grandes edifícios do passado e as arquiteturas vernaculares, construídas com materiais e recursos do próprio meio onde está inserida, têm semelhanças com conceitos matemáticos essenciais. O autor afirma que uma delas é uma estrutura de fractal, verificável em todos os níveis de ampliação, e os diferentes níveis de escala muito firmemente ligados pelo design. Destaca que os edifícios modernistas já não possuem características fractais pois possuem poucas escalas, as quais não mantêm proporção entre si e que existe uma intenção, não escrita, em evitar a organização de escalas. 
Assim, segundo o autor, um dos objetivos do modernismo foi eliminar qualquer interface arquitetônica com dimensão fractal que foram substituídas por linha retas, seguindo o alinhamento rigoroso dos edifícios. Indica também que o motivo foi limpar a confusão percebida das cidades mais antigas, ainda que essa confusão fosse realmente a complexidade organizada.

Desse modo, Salingaros (2004) [19] afirma que em cursos de Arquitetura e Urbanismo existe esse impasse, pois o estilo modernista apresentado aos acadêmicos está em contradição com a estrutura organizativa das formas de vida. Segundo ele, a fractalidade percebida nas construções das cidades mais antigas está sendo substituída por regras estilísticas arbitrárias, o que tem levado a uma separação filosófica, psicológica e física do ser humano de seu ambiente. O autor conclui que, nesse sentido, a cidade contemporânea, onde se destaca ao estilo moderno, falha como um ambiente natural para crianças e adolescentes.

Em contrapartida, Martins e Librantz (2006) [20] destacam a existência de tendências atuais relativas ao urbanismo e ao planejamento urbano, nas quais se percebe, novamente, a valorização da escala humana e a participação e variedade de escalas que podem encontrar uma explicação científica nos conceitos apresentados pela geometria fractal. Esclarecem que, nesses casos, os estudos se valem de uma das mais importantes características do fractal: a autossimilaridade, propriedade que permite a simetria por meio de vários níveis escalares. Segundo os autores, em razão da ampla possibilidade de uso da geometria fractal na elaboração de análises e proposições nas áreas de projeto urbano, desenho urbano e planejamento urbano regional, eles verificam a relevância de pesquisas investigativas, no cenário científico, sobre possibilidades de aplicações de tais conceitos em projetos arquitetônicos.

Nesse sentido, apresenta-se os procedimentos utilizados na investigação realizada referentes às possibilidades de usos de padrões fractais na construção do projeto de um mobiliário urbano, no caso um ponto de ônibus, tendo em vista explorar a beleza da simetria e a otimização de recursos que podem ser propiciadas pelo uso desses padrões.

\section{MATERIAL E MÉTODOS}

O projeto "Uma metodologia para estudo de padrões fractais aplicáveis na arquitetura e urbanismo", iniciado em 2010, foi retomado no ano de 2016 com o objetivo de realizar estudos para propor a construção de um ponto de ônibus a partir dos conceitos de geometria fractal, abrigo, informação, estética, transparência, proteção de acesso ao ônibus e acessibilidade.

Os trabalhos iniciaram com a visualização de vídeos da série "Fractais caçando a dimensão oculta (dublado)" - partes 1, 2, 3 e 4 [21, 22, 23, 24] sobre geometria na natureza. Após assistir aos vídeos e discutir sobre o desenvolvimento dos fractais e sobre suas diferenças em relação aos mosaicos, passou-se à construção de alguns fractais em papel os quais são apresentados a seguir.

\subsection{Construção do fractal Quartil Central e do fractal Árvore Pitagórica}

O fractal Quartil Central (Figura 1) foi construído a partir de dobradura e recorte usando a técnica Kirigami, que é uma variação do origami, uma arte japonesa de recorte e colagem de papéis. Segundo Kobayashi e Yamada (2013, p. 148) [25]:

[...] O KIRIGAMI, técnica mista que, além de utilizar as dobras no papel (como no origami), utiliza cortes ("kiru" - verbo "cortar"), pode ser feito com base em um papel de gramatura maior que do origami e, ao se introduzirem alguns cortes, pode-se dobrá-lo para formar as figuras desejadas. [...]

Nesse trabalho, é possível perceber que a estrutura nas suas partes, constituídas por prismas, é similar ao todo e que sua dimensão é fracionária. Cada módulo menor possui sua aresta medindo a metade da aresta do módulo anterior. 


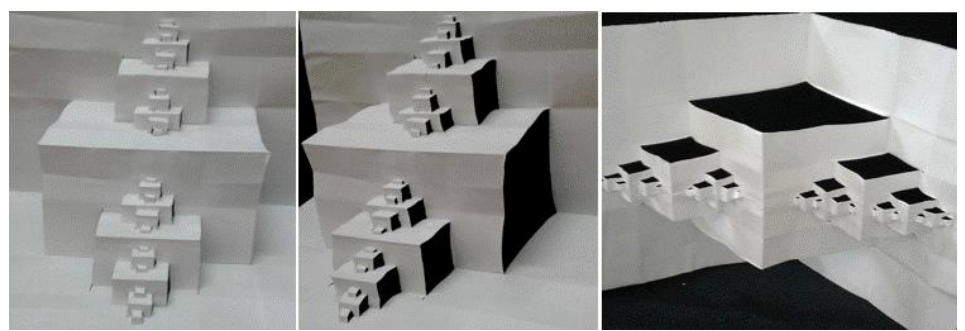

Figura 1: Fractal Quartil Central feito em papel com a técnica Kirigami, elaborado pelos autores.

O fractal árvore pitagórica em 3D (Figura 2), por sua vez, foi construído a partir de recorte, dobradura e colagem de folhas de papel color set. Os cubos iniciais possuem as dimensões do menor terno pitagórico de números inteiros, ou seja, possuem suas arestas com as dimensões três, quatro e cinco centímetros. A partir do primeiro módulo, cada cubo formará, com outros dois cubos, um novo terno pitagórico. As arestas dos cubos de cada novo módulo são calculadas por meio de uma regra de três simples.

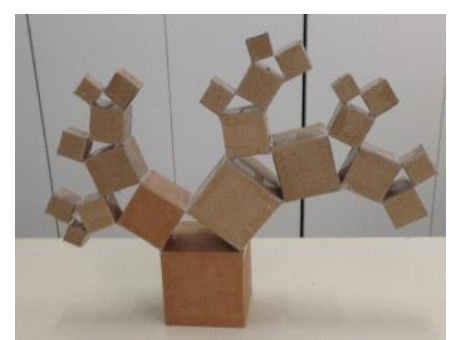

Figura 2: Fractal Árvore pitagórica em 3D elaborado pelos autores.

Após a construção de alguns padrões fractais e discussões para compreender as caraterísticas principais dos fractais, como autossimilaridade, dimensão fracionária e processo recursivo, o trabalho foi direcionado para estudo do conceito do ponto de ônibus.

\subsection{Estudo do conceito do ponto de ônibus: características e medidas padrões necessárias}

Para se definir as medidas ideais para o ponto de ônibus foram pesquisadas normas da ABNT e outras referências [26, 27, 28, 29]. A NBR 9283 [26] define paradas de ônibus como mobiliário urbano, na subcategoria de circulação e transporte, incluindo abrigos e pontos de ônibus em suas diversas modalidades.

Em reportagem publicada no Jornal da tarde, em 7 de março de 2010, Frota (2010) [27] apresenta resultados de uma pesquisa realizada em São Paulo com usuários de coletivo urbano para saber como seria, na visão desses sujeitos, o ponto de ônibus ideal. A reportagem mostra o que o paulistano considera indispensável num ponto de ônibus e como seria a estrutura que consideram ideal. A maioria das pessoas pediu cobertura e proteção lateral nos abrigos, além de câmeras de vigilância, lixeiras, espaço para cadeirantes, letreiros com itinerário dos coletivos e cobertura de acesso até o embarque. Na Figura 3 é possível observar como seria o ponto de ônibus ideal na perspectiva dos usuários de coletivo urbano de São Paulo. 


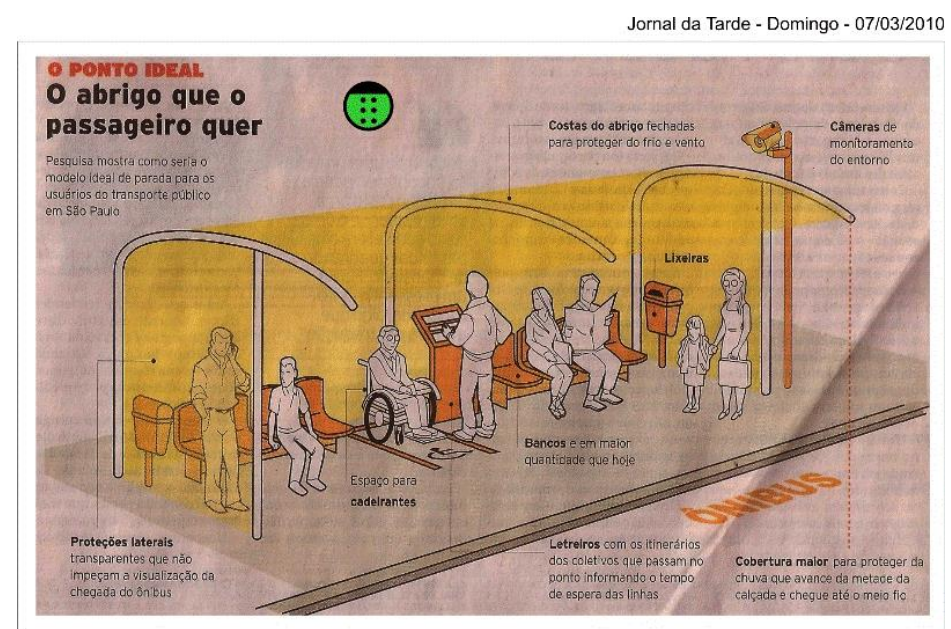

Figura 3: Ponto de onibus ideal na perspectiva do paulistano Fonte: Frota (2010) [27]

O Caderno Técnico para Projetos de Mobilidade Urbana - Sistemas de Prioridade ao Ônibus ([28], p 28) apresenta os critérios gerais para a implantação de infraestrutura urbana de modo que sejam garantidas a segurança e a acessibilidade (Figura 4) e prevê que:

[...] a área correspondente ao embarque, desembarque e circulação de passageiros deve estar livre de obstáculos que interfiram na circulação das pessoas, inclusive daquelas com mobilidade reduzida. Com relação ao mobiliário a ser implementado em terminais, estações e pontos de parada deve conter, no mínimo, abrigo contra intempéries, assentos ou bancos semissentados, lixeiras e iluminação, e sistema de informação ao usuário.

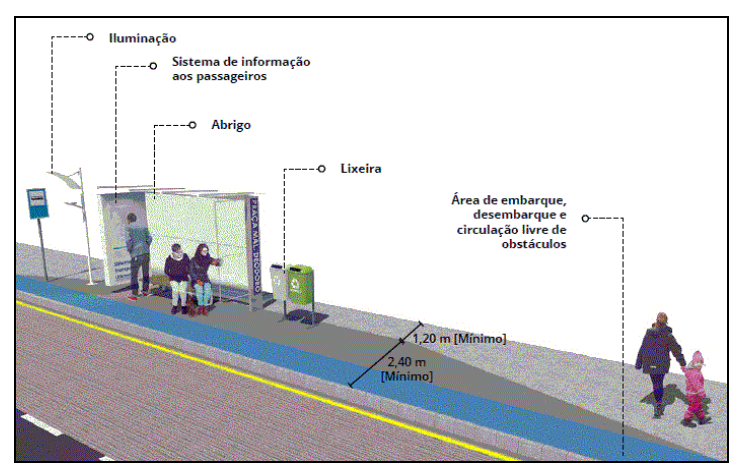

Figura 4: Características que devem estar presentes em projetos de pontos de parada de um sistema prioritário ao ônibus. Fonte: Brasil (2016)[28]

Com referência às medidas mínimas, essa publicação ([28], p 31) recomenda:

[...] os pontos de parada devem ter largura mínima de $2,40 \mathrm{~m}$, sendo $1,20 \mathrm{~m}$ destinado à instalação do abrigo e $1,20 \mathrm{~m}$ de espaço para o embarque e desembarque de passageiros, bem como para a projeção da cobertura do abrigo; e, garantir $1,20 \mathrm{~m}$ de largura da faixa livre para circulação atrás dos pontos de parada.

Para auxiliar na determinação das medidas a serem utilizadas, foi fotografado o local onde o grupo pretende propor a instalação do ponto de ônibus experimental junto ao prédio onde o curso de Arquitetura fica instalado na Universidade na qual foi realizada a pesquisa (Figura 5). 


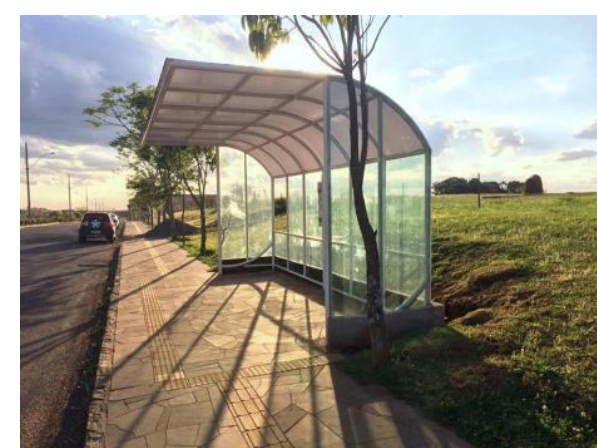

Figura 5: Abrigo de ônibus existente na Universidade na qual foi realizada a pesquisa. Fonte: Autores.

Analisando-se o número médio provável de usuários, alunos e funcionários do edifício próximo à potencial instalação, chegou-se à quantidade média aproximada de 15 a 25 pessoas reunidas no ponto de ônibus, a cada 30 minutos. A área para receber tal número de pessoas foi definida com base em informações antropométricas levando em conta o espaçamento lateral necessário [29].

A partir dos estudos de padrões fractais e dos conceitos envolvendo o "ponto de ônibus ideal", estabeleceu-se os seguintes critérios para a construção do projeto de ponto de ônibus, que deveria:

(i) ser gerado a partir de um padrão fractal;

(ii) servir de abrigo aos usuários;

(iii) ter espaços para divulgação de informações relevantes;

(iv) ter cobertura para acesso do ônibus;

(v) ter transparência e

(vi) considerar o número de pessoas que transita pelo local, para estimar sua capacidade.

A partir dessas definições, passou-se para o estudo de propostas observando-se os conceitos estabelecidos. Cada proposta passou por análises matemáticas e por análises de viabilidade estrutural, tendo em vista a escolha de um padrão fractal adequado que atendesse às necessidades vigentes.

\section{RESULTADOS E DISCUSSÃO}

Ao ser analisada a primeira proposta (Figura 6), verificou-se que ela não se enquadrava no conceito geometria fractal pois não havia similaridade das partes com o todo, visto que a forma dos módulos constituía um prisma de base quadrada mas a forma do objeto todo correspondia a duas pirâmides de base quadrada unidas pelo vértice.

A segunda proposta (Figura 7) foi pensada a partir do fractal Quartil Central ou Degraus Centrais, sendo a estrutura central e a cobertura variações do mesmo fractal. Nesse caso, verificou-se que a proposta contempla o conceito de geometria fractal, entretanto não contempla o conceito abrigo, de modo que as pessoas ficariam expostas às variações do tempo como vento e chuvas fortes.
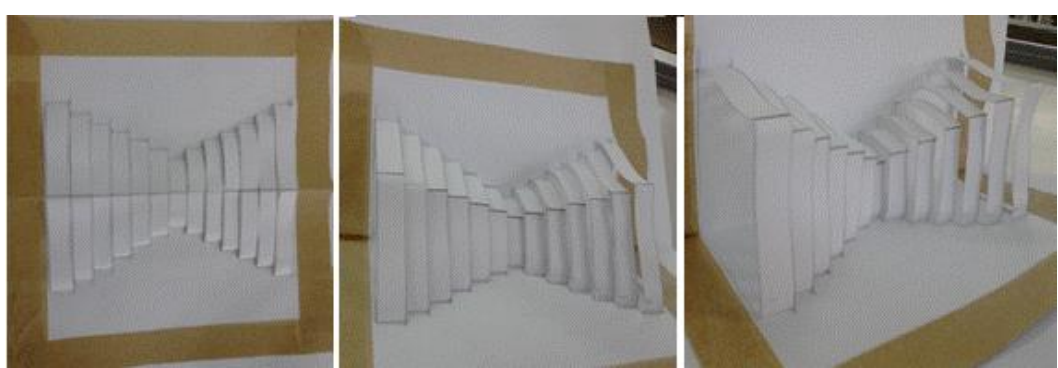

Figura 6: Primeira proposta de Abrigo de ônibus elaborado pelos autores. 

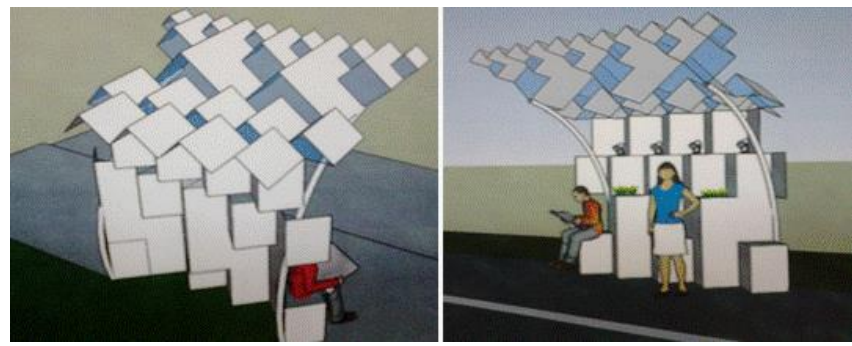

Figura 7: Perspectiva frontal e posterior da proposta 2 elaborado pelos autores.

Em seguida, foi considerada outra proposta (Figura 8), na qual a inspiração ainda é o fractal Degraus Centrais. Nessa proposta, houve a incorporação de outras formas - a exemplo da espiral - como estrutura de apoio que sustenta a estrutura superior. Além disso, o desenvolvimento da cobertura partiu da ideia apresentada na Figura 2 e, portanto, mantém a não similaridade da parte como o todo.
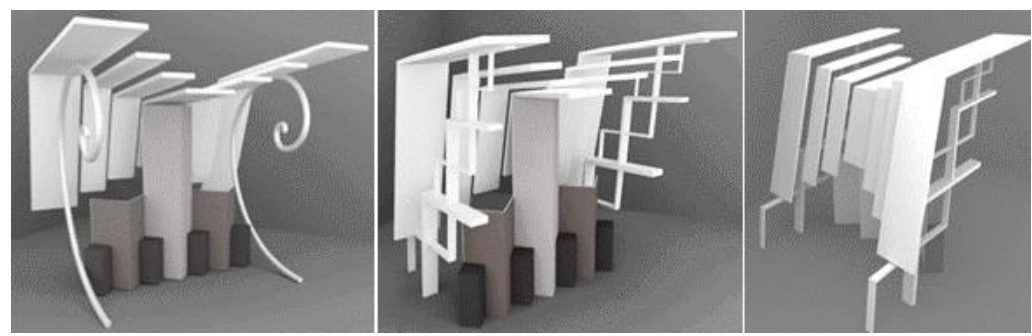

Figura 8: Proposta 3 do Abrigo de ônibus elaborado pelos autores.

A quarta proposta (Figura 9) envolveu dois estudos diferentes de cobertura para o "corpo" já apresentado nas figuras anteriores. No primeiro, uma cobertura translúcida envolve parte da espiral Fibonacci e, no segundo, a estrutura quartil central foi repetida na cobertura.

Verificou-se que as propostas 2 e 3 apresentavam problemas de permeabilidade, o que deve ser evitado em uma parada de ônibus pois as pessoas precisam ficar protegidas do vento e da chuva nesses espaços. Assim, as ideias foram desconsideradas.

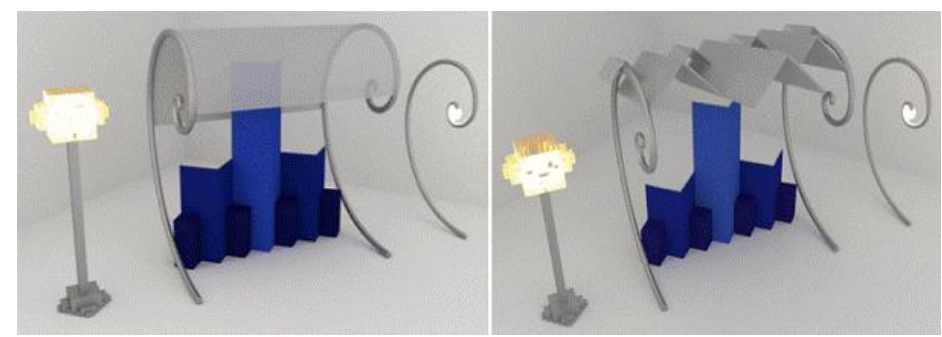

Figura 9: Proposta 4 de abrigo de ônibus elaborada pelos autores.

Posteriormente, se pensou em uma quinta proposta (Figura 10), na qual foi utilizada uma estrutura de prismas, em desníveis, com forma quadrangular. Essa forma pode ser observada na parte e no todo da estrutura, observando-se o conceito de Geometria Fractal. Cada quadrado da sequência tem a metade da aresta do quadrado anterior, porém verificou-se que a proposta não atendia ao conceito abrigo.
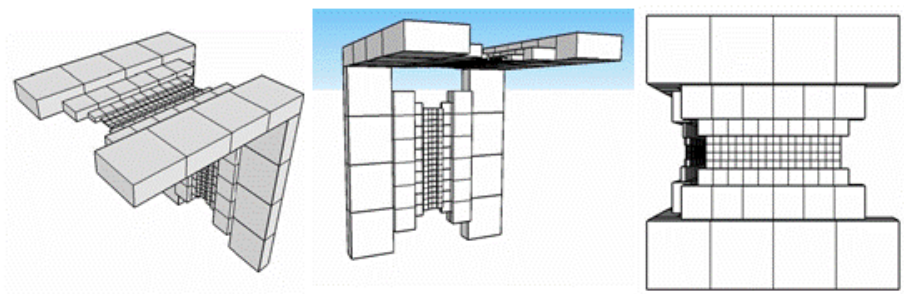

Figura 10: Proposta 5 com perspectivas e vista superior de abrigo de ônibus elaborada pelos autores. 
A proposta evidenciada na Figura 10 apresenta plasticidade contudo, no conjunto, se apresentou como uma estrutura pesada e com problemas não resolvidos como o abrigo do vento e da chuva. Além disso, não há assentos, ou seja, o conceito de abrigo também não foi contemplado.

Em relação a essas propostas iniciais, observou-se que, ao serem considerados padrões diferentes na mesma estrutura, a harmonia do conjunto poderia ser prejudicada. Outra questão apontada foi a ausência do conceito abrigo em todas essas propostas analisadas. Assim, a análise das propostas a partir dos conceitos estabelecidos para o ponto de ônibus indicou que era preciso trabalhar mais sobre os pontos que apareceram como fragilidades nos projetos idealizados.

A análise inicial dos resultados indicou a necessidade de serem considerados parâmetros numéricos reais e específicos para a elaboração do projeto a ser executado e que abrigassem confortavelmente as pessoas. Além disso, em relação ao problema relacionado ao número de pessoas que o espaço delimitado deveria abrigar, concluiu-se que essa questão poderia ser solucionada tão somente com a ampliação do bloco (fractal Quartil Central) ou com a colocação de módulos consecutivos da mesma proposta.

Após a identificação dos problemas nas propostas, surgiu uma nova proposta inspirada na variação do fractal Mediatriz, ilustrado na Figura 10, mesclada com o fractal Gaxeta de Sierpinski Modificada, ilustrado na Figura 11.

O fractal Mediatriz foi criado pelo grupo e, por conseguinte, não existe na literatura um fractal com esse nome. Foi criado a partir da divisão de segmentos em partes iguais por um processo de mesmo nome. As divisões decorrentes desse processo são limitadas ao número de partes iguais à potência de 2 , ou seja, $2,4,8,16$ e assim infinitamente. Se o fractal plano gerador é um fractal originado pelo processo das mediatrizes, ele pode ser formado por um ângulo de $30^{\circ}, 45^{\circ}$ ou $60^{\circ}$. No caso deste estudo, optou-se pelo ângulo de $60^{\circ}$ para que a linha lateral não ficasse muito oblíqua ao se olhar de frente.

Inicialmente, traça-se um segmento de reta $\mathrm{AB}$ que se pretende dividir. Pelos seus extremos, traça-se uma linha com o esquadro em $60^{\circ}$ e onde essas linhas se cruzam forma-se um ponto, ou vértice $\mathrm{C}$ do triângulo. A partir desse ponto é traçada uma linha reta até a base do triângulo. Essa reta $\mathrm{CM}$ é a mediatriz do segmento $\mathrm{AB}$ e divide o segmento ao meio. A seguir, repete-se o procedimento em cada metade do segmento, obtendo-se os níveis II e III e assim sucessivamente (Figura 11). Esse processo é denominado de recursivo e tende ao infinito.

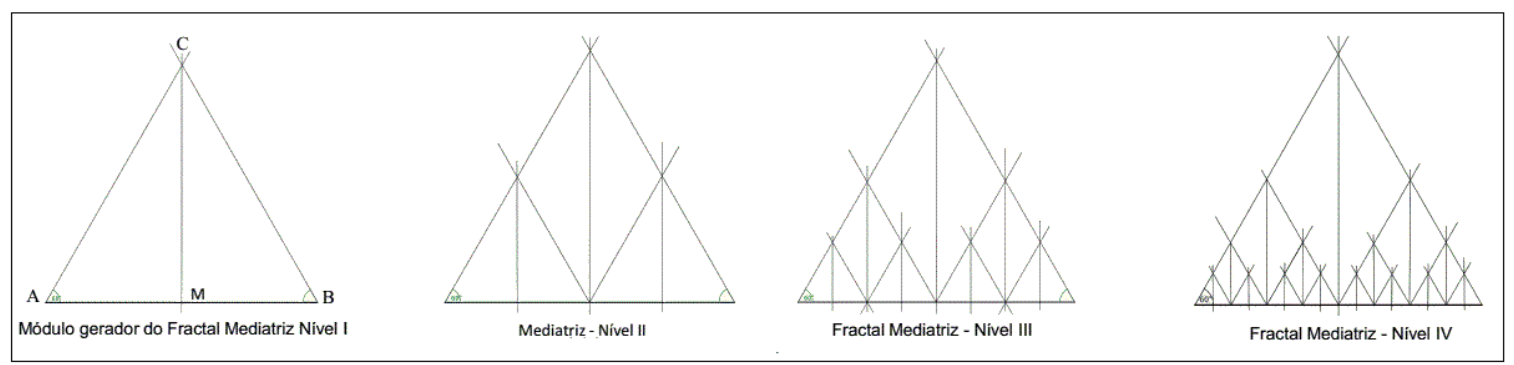

Figura 11: Construção do Fractal Mediatriz no programa GeoGebra elaborado pelos autores.

Já o fractal Gaxeta de Sierpinski Modificada, denominado por Barbosa (2002) [12] como um dos monstros matemáticos famosos, refere-se à curva ou ao triângulo de Sierpinski (Figura 12).
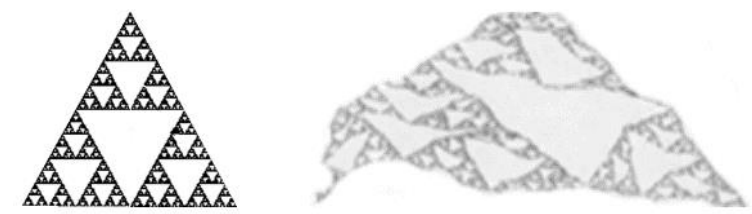

Figura 12: Triângulo ou Gaxeta de Sierpinski e a variação Gaxeta de Sierpinski Modificada. Fonte: Ramalho (2015) [30] 
Uma das características fundamentais dos fractais é a autossimilaridade. Um padrão fractal pode se desenvolver por meio de um processo de autossimilaridade exata ou aproximada [12]. Nos fractais geométricos, é possível constatar a similaridade inegável da parte com o todo como no fractal Triângulo de Sierpinski (Figura 12). A similaridade exata existe quando cada parte é incontestavelmente semelhante ao todo. Entretanto, há outro tipo de similaridade nos fractais, a similaridade não exata, como nos fractais produzidos por meio de equações de números complexos [12]. Como exemplo, Ramalho (2015) [30] apresenta os fractais conjuntos de Mandelbrot e Júlia (Figura 13) e a Gaxeta de Sierpinski Modificada (Figura 12).

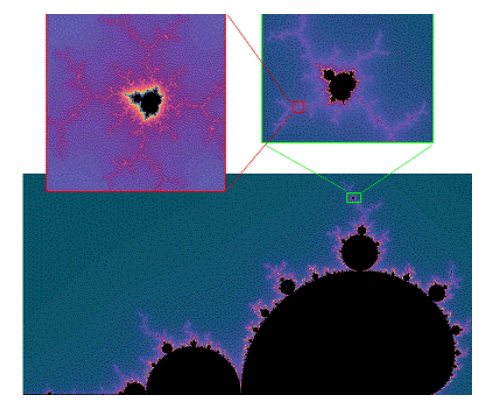

Figura 13: Conjunto de Júlia. Autossimilaridade aproximada (não exata). Fonte: Ramalho (2015) [30]

De acordo com Ramalho (2015) [30], o processo de construção da variação da Gaxeta de Sierpinski inicia com um triângulo arbitrário, tal como ocorre na construção do triângulo de Sierpinski. No triângulo inicial, aplica-se o procedimento chamado de TSG que consiste em remover o triângulo médio do triângulo original formado pela união dos pontos médios dos lados do triângulo. A seguir, desloca-se cada um dos pontos médios dos lados do triângulo para baixo ou para cima, de forma aleatória. Após concluída a primeira aplicação do processo TSG se obtém três triângulos sólidos unidos pelos vértices, formando um triângulo vazado entre eles (ver Figura 14).

Para cada um dos triângulos sólidos, obtidos no primeiro procedimento, repete-se o processo TSG. Obtém-se, desse modo, nove triângulos sólidos e quatro triângulos vazados. A partir daí, aplica-se repetidamente o procedimento TSG a cada um dos triângulos sólidos. Quando o procedimento TSG é repetido ao infinito, obtém-se a Gaxeta de Sierpinski Modificada (Figura 14) [30].

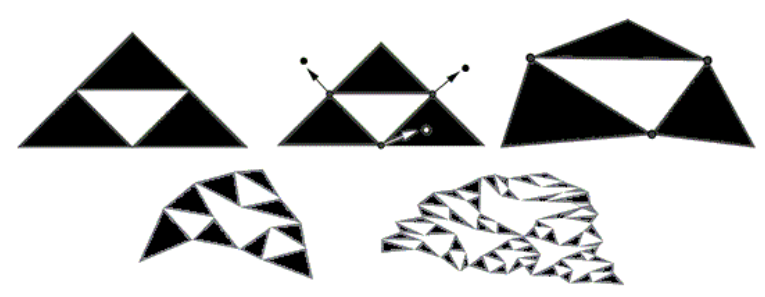

Figura 14: Construção da Gaxeta de Sierpinski Modificada elaborada pelos autores

Conforme Ramalho (2015) [30], é possível constatar que a Gaxeta de Sierpinski Modificada se assemelha ao aspecto inconfundível de uma montanha (Figura 15). Após, adiciona-se alguns efeitos de sombra, luz e cor, podendo-se obter uma imagem muito semelhante a uma montanha real. Alterando-se a forma do triângulo original é possível mudar a forma da montanha e alterando-se as regras da distância permitida para os movimentos aleatórios pode-se também alterar sua textura (Figura 15).

Ramalho (2015) [30] esclarece que independentemente da forma do triângulo original e das variações de cor, sombra e luz, tal como ocorre na natureza, a imagem resultante terá sempre o inconfundível aspecto de montanha. A autossimilaridade aproximada, ou não exata, será constatada quando, ao olhar para um objeto e para as partes desse objeto em diferentes escalas, forem observadas estruturas reconhecidamente idênticas, porém não similares. $O$ autor ainda afirma que a autossimilaridade aproximada é uma propriedade comum de vários objetos e formas 
naturais tais como montanhas, nuvens, árvores, plantas, pulmão, coração e sistema vascular humano, entre outros.

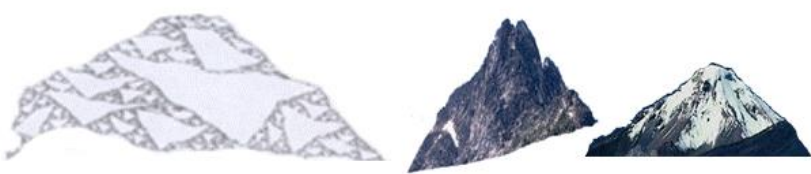

Figura 15: A Gaxeta de Sierpinski Modificada após o oitavo passo. Fonte: Ramalho (2015)[30].

A partir das dimensões consideradas para a construção real da parada de ônibus foram discutidas alterações e adequações no projeto tendo em vista adequar ao fractal mediatriz, em função de sua exequibilidade e estética, alterando o ângulo inicial de $60^{\circ}$ para $45^{\circ}$, pois independente do grau seria necessário complementar a estrutura com o fractal "Gaxeta de Sierpinski modificada", construído em 3D, para o fechamento das laterais do ponto de ônibus.

Assim, a proposta final, que pode ser visualizada na Figura 16, partiu do fractal plano Mediatriz em $45^{\circ}$ e sua cobertura, pela forma curva, se aproxima do fractal Gaxeta de Sierpinski Modificada em 3D. Apresenta um aspecto moderno, de estrutura translúcida (Figuras 16, 17 e 18) que, além do abrigo e da proteção concernentes às variantes climáticas, permite despertar a sensação de integração ao ambiente externo, possibilitando, por exemplo, a visualização do verde da vegetação, do colorido das flores e do azul do céu.

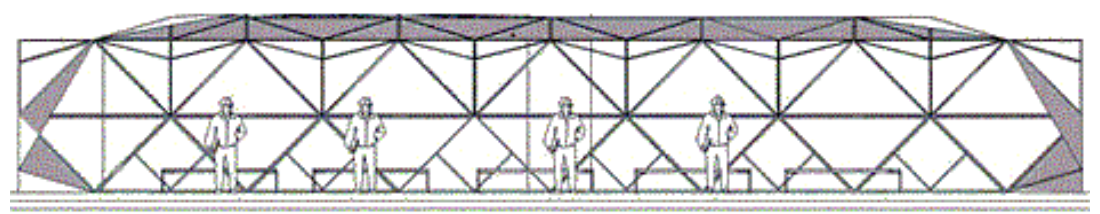

Figura 16: Vista frontal do abrigo de ônibus elaborado pelos autores

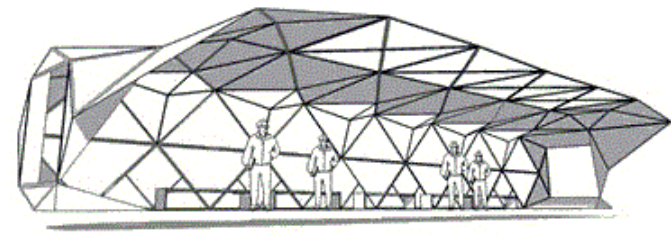

Figura 17: Perspectiva do abrigo de ônibus elaborado pelos autores

De acordo com os conceitos de parada de ônibus considerados pelo grupo, verifica-se que a proposta final abriga e protege os usuários das variantes do tempo, sendo ampla o suficiente para abrigar o número aproximado de pessoas usuárias considerado.

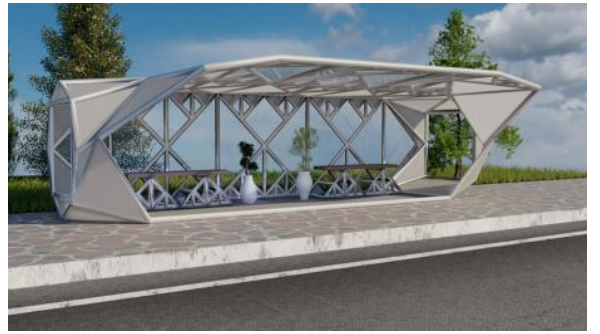

Figura 18: Proposta final - Renderização elaborada pelos autores

Além disso, destaca-se que no projeto também são previstos assentos para acomodar melhor as pessoas, bem como estão previstos espaços livres nos quais podem ser disponibilizadas informações tanto sobre horários e tempo de espera das linhas de ônibus, bem como sobre a 
própria concepção da estrutura arquitetônica como textos explicativos sobre as figuras geométricas fractais, geradoras da estrutura construída

\section{CONSIDERAÇÕES FINAIS}

A proposta da presente pesquisa tem como premissa a inovação estética, o ensino por meio da participação dos acadêmicos bolsistas, a aplicabilidade dos resultados e a difusão do conhecimento gerado.

Após um ano de estudos sobre a aplicação de padrões fractais em projetos de arquitetura e design para projeto de um abrigo de ônibus, uma conclusão inicial foi que os resultados indicam que seria inviável usar um padrão fractal único na elaboração do projeto, tendo em vista a necessidade de atender aos critérios técnicos estabelecidos. Também foi possível concluir que a mistura de vários padrões fractais na estrutura central levou a concepções de projetos que não foram considerados esteticamente bonitos.

Além disso, percebeu-se que deveria ser utilizado um único padrão na estrutura central e que os fechamentos necessários poderiam ser realizados com usos de outro padrão fractal, de modo a possibilitar o fechamento adequado.

Assim, na proposta final de ponto de ônibus, que é uma estrutura oca e aberta, que foi projetada tendo em vista o uso de padrões fractais, a funcionalidade e a viabilidade estrutural necessitou a mescla de dois padrões fractais, o fractal Mediatriz e a Gaxeta de Sierpinski Modificada. Além disso, para respeitar as dimensões reais incialmente estabelecidas, também foi preciso trabalhar com mosaico de fractal, adaptando recortes do fractal mediatriz.

$\mathrm{Na}$ percepção do grupo, a estrutura final está esteticamente bem solucionada e contempla os conceitos de fractal e de parada de ponto de ônibus inicialmente estabelecidos. Como investigações futuras, pretende-se introduzir outros conceitos que não foram contemplados na proposta original, tais como acessibilidade para pessoas com necessidades especiais, lixeira e iluminação envolvendo padrões fractais.

A geometria fractal está relacionada ao mundo da natureza, da arte, da tecnologia e do pensamento matemático. Como exemplos concretos dessas relações, destacam-se os resultados verificados na execução do presente projeto de pesquisa, nos quais evidencia-se a possibilidade da utilização efetiva dos raciocínios de geometria fractal na elaboração do projeto de uma parada de ponto de ônibus e de sua contribuição estética, que também possibilitam perceber a possibilidade de aplicação da geometria fractal em construções arquitetônicas diversas.

Os estudos sobre a aplicação de padrões fractais no mobiliário urbano não se resumem ao caso apresentado neste artigo. O grupo segue investigando sobre novas possibilidades de uso de padrões fractais, tendo em vista contribuir para uma arquitetura diferenciada e esteticamente interessante.

\section{AGRADECIMENTOS}

Agradecemos às participações voluntárias, na presente pesquisa, dos discentes Alex Garcia Borges e Natália P. Paggotto, ambos do curso de Arquitetura e Urbanismo da UPF, e do discente Lucas Silva Stein, do curso Design de Produto da UPF, pelas contribuições no processo investigativo e pelas construções virtuais, que possibilitaram visualizar as propostas idealizadas.

\section{REFERÊNCIAS BIBLIOGRÁFICAS}

1. Souza EE. Geometria e Arquitetura. Revista Eletrônica de Arquitetura e Urbanismo (Arq. Urb). 2008. 1: 105-118. Disponível em <http://www.usjt.br/arq.urb/numero_01/artigo_06_180908.pdf> Acesso em: 15 de setembro de 2017.

2. Ching FDK. Arquitetura, forma, espaço e ordem. São Paulo: Martins Fontes; 2012, 399 p.

3. Forbes RJ; Dijksterhuis EJ. História da Ciência e da Técnica: obedecendo a natureza, conquistá-la: Da antiguidade ao século XVII. $1^{\mathrm{a}}$ ed. Lisboa: Ulisseia; 1963. 
4. Waihrich, LP et al. Pesquisa de padrões e suas aplicações em arquitetura e urbanismo: ênfase em Geometria Fractal. Proceedings of the XXXI Iberian-Latin-American Congress o n Computational Methods in Engineering, 2010, Buenos Aires, Argentina: Asociación Argentina de Mecânica Computacional, 2010, p. 6341-6359.

5. Le Corbusier. Por uma Arquitetura. 5ed. São Paulo: Perspectiva; 2014. 205p. (Estudos; 27).

6. Ching FDK. Dicionário Visual de Arquitetura. São Paulo: Martins Fontes, $3^{\mathrm{a}}$ Ed; 2012, 320 p.

7. Silva, E. Uma introdução ao projeto arquitetônico. Porto Alegre: Universidade Federal do Rio Grande do Sul; 1991. 122 p.

8. Mandelbrot BB. The Fractal Geometry of Nature. New York: W. H. Freeman; 1983.

9. Mandelbrot BB. Objetos fractais: forma, acaso e dimensão seguido de panorama da linguagem fractal. 2 ed. Lisbon: Gradiva; 1998 (Portuguese trans. of Les objects fractals).

10. Sedrez MR; Pereira ATC. Fractal Shape.Nexus Network Journal. 2012;14(1):97-107.

11. Barthel R. Architecture et Bionique constructions naturelles. Paris: Editions Delta \& Spes; 1985. 151 p.

12. Montenegro GA. Geometria descritiva. São Paulo: Edgard Blücher; 1991.

13. Barbosa RM. Descobrindo a geometria fractal para a sala de aula. Belo Horizonte: Autêntica; 2002.

14. Baptista TRF. Fractais - aplicações em engenharia. 2013. 76 p. Dissertação (Mestrado em Engenharia Electrotécnica e de Automação Área de Especialização de Automação e Sistemas) - Departamento de Engenharia Electrotécnica, Instituto Superior de Engenharia do Porto, Porto, Portugal, 2013.

15. Bernardes AA. Encapsulamento de metalocenos em óxidos binários tipo $\mathrm{SiO} 2-\mathrm{CrO} 3, \mathrm{SiO} 2-\mathrm{MoO} 3 \mathrm{e}$ SiO2-WO3 através do método sol-gel não-hidrolítico: sistemas modificados com grupos organosilanos. [Tese -Doutorado]. Porto Alegre (RS/BR): Universidade Federal do Rio Grande do Sul - Instituto de Química - Programa de Pós-Graduação em Ciência dos Materiais, 2014. 132 f.

16. Cruz A et al. Codificação Fractal de Imagens. Revista Telecomunicações. 2008;11(1):14-23. Disponível em: < http://www.inatel.br/revista/busca/147-2-codificacao-fractal-de-imagens-s823358-1/file>. Acesso em: 18 out. 2017.

17. Amaral LAN; Ivanov PC; Havlin S; Goldberger AL; Stanley HE. Multifractalidade do Ritmo Cardíaco. Gazeta de Física. 1999 Oct;22(4):4-10. Disponível em: <http://nautilus.fis.uc.pt/gazeta/revistas/22_4/004-009.300.pdf>. Acesso em: 18 out. 2017.

18. Rodriguez J; Prieto S; Posso H; Cifuentes R; Correa C; Soracipa Y; López F; Méndez L; Bernal HJ; Salamanca A. Fractales: ayuda diagnóstica para células preneoplásicas y cancerígenas del epitelio escamoso cervical confirmación de aplicabilidad clínica. Revista Med (rev.fac.med). 2016 Jan;24(1):7988. Disponível em: <http://www.scielo.org.co/scielo.php?script=sci_arttext\&pid=S012152562016000100007\&lng=es\&nrm=iso>. Acesso: 19 out. 2017.

19. Salingaros NA. Connecting the Fractal City. Department of Mathematics, University of Texas at San Antonio, San Antonio, Texas 78249, USA. PLANUM -- The European Journal of Planning On-line (March 2004). Disponível em: <http://zeta.math.utsa.edu/ yxk833/connecting.html> Acesso em: 17 out. 2017.

20. Martins AMSM; Librantz, AFH. A geometria fractal e suas aplicações em arquitetura e urbanismo. Exacta. 2006 Nov;4(n. especial):91-93.

21. Fractais. Caçando a dimensão fractal dublado Parte 1. Consciência Universal. KPBS. San Diego, 12 julh. 2016a. 15,19 min. Disponível em: <https://www.youtube.com/watch?v=bfmVqUjX4kk>. Acesso em: 18 set. 2017.

22. Fractais. Caçando a dimensão fractal dublado Parte 2. Consciência Universal. KPBS. San Diego, 12 julh. 2016b. 15,19 min. Disponível em: <https://www.youtube.com/watch?v=ere4leD-aRQ>. Acesso em: 18 set. 2017.

23. Fractais. Caçando a dimensão fractal dublado Parte 3. Consciência Universal. KPBS. San Diego, 12 julh. 2016c. 15,19 min. Disponível em: < https://www.youtube.com/watch?v=CPCvL4QkgX4>. Acesso em: 18 set. 2017.

24. Fractais. Caçando a dimensão fractal dublado Parte 4. Consciência Universal. KPBS. San Diego, 12 julh. 2016d. 15,19 min. Disponível em: < https://www.youtube.com/watch?v=GDAMjUq5cE4>. Acesso em: 18 set. 2017.

25. Kobayashi MCM; Yamada TRU. Origami e Kirigami: arte e cultura como recurso lúdico e educativo. Revista Ciência em Extensão. 2013 Set;9(3):148-158.

26. Abnt. Associação Brasileira de Normas Técnicas. NBR 9283: Mobiliário urbano - Classificação. Rio de Janeiro; 1986.

27. Frota T. Ponto de ônibus. Prefeitura de São Paulo definirá padrões para os pontos de ônibus. 2010. Disponível em:<https://thaisfrota.wordpress.com/2010/03/page/2/>. Acesso em: 22 de setembro de 2017.

28. Brasil. Ministério das Cidades. Secretaria Nacional de Mobilidade Urbana. Caderno Técnico para Projetos de Mobilidade Urbana - Sistemas de Prioridade ao Ônibus. Brasília: MC, 2016. 175 p. 
29. Panero J; Zelnik M. Dimensionamento humano para espaços interiores. São Paulo: GGBrasil; 2014. 3200.

30. Ramalho PG. Geometria fractal: o jogo do caos. 2015. Disponível em: <http://slideplayer.com.br/slide/5029580/>. Acesso em: 02 de out. de 2017 